TITLE:

\title{
Ecosystem consequences of selective feeding of an insect herbivore: palatability- decomposability relationship revisited
}

\author{
$\operatorname{AUTHOR}(\mathrm{S}):$ \\ KAGATA, HIDEKI; OHGUSHI, TAKAYUKI
}

\section{CITATION:}

KAGATA, HIDEKI ... [et al]. Ecosystem consequences of selective feeding of an insect herbivore: palatability-decomposability relationship revisited. Ecological Entomology 2011, 36(6): 768-775

\section{ISSUE DATE:}

2011-11-18

URL:

http://hdl.handle.net/2433/197185

\section{RIGHT:}

This is the peer reviewed version of the following article: KAGATA, H. and OHGUSHI, T. (2011), Ecosystem consequences of selective feeding of an insect herbivore: palatability-decomposability relationship revisited. Ecological Entomology, 36: 768-775, which has been published in final form at http://dx.doi.org/10.1111/j.1365-2311.2011.01327.x; この論文は 出版社版でありません。引用の際には出版社版をご確認ざ利用ください。; This is not the published version. Please cite only the published version. 


\section{Ecosystem consequences of selective feeding of an insect}

\section{herbivore: palatability-decomposability relationship revisited}

HIDEKI KAGATA and TAKAYUKI OHGUSHI

5 Center for Ecological Research, Kyoto University, Japan

Correspondence: Hideki Kagata

Center for Ecological Research, Kyoto University,

10 Hirano 2-chome, Otsu, Shiga, 520-2113, Japan.

E-mail: kagata@ecology.kyoto-u.ac.jp

Tel: +81-77-549-8214

Fax: +81-77-549-8201

15 Running title: Palatability and decomposability 


\section{Abstract.}

1. Relationship between leaf palatability and litter decomposability is critical to understanding the effects of selective feeding by herbivores on decomposition processes, and several studies have reported that there is a positive relationship between them.

2. However, palatability is not always positively correlated with decomposability, because of species-specific feeding adaptation of herbivores to host plants. Moreover, the effects of selective feeding by herbivores on soil decomposition processes should be understood in terms of the inputs of leaf litter and excrement.

3. The present study examined the relationships between leaf palatability and the decomposability of litter and frass, using Lymantria dispar (L.) (Lepidoptera: Lymantriidae) and 15 temperate deciduous tree species.

4. Larvae of $L$. dispar exhibited a clear feeding preference, and subsequently the excreted frass mass differed among tree species. Litter and frass decomposability also differed among tree species, and frass was more rapidly decomposed than litter. There were no positive or negative correlations between palatability and decomposability of litter and frass. 
5. These results indicate that $L$. dispar larvae may accelerate the decomposition process in temperate deciduous forests through selective feeding on plants with relatively low litter decomposability and the production of frass with higher decomposability than the litter.

Keywords: Decomposition, frass, host plant selection, Lymantria dispar, plant-insect interaction. 
Insect herbivores can influence soil decomposition processes through various pathways

(Wardle and Bardgett 2004): changes in the quality and quantity of litter due to selective feeding on preferred plants and herbivore-induced plant responses (Chapman et al. 2003; Schmitz 2009) and return of the waste products and carcass to soil (Christenson et al. 2002;

Yang 2006; Frost \& Hunter 2007). The relationship between leaf palatability and litter decomposability is one of the factors determining the direction of effects of selective feeding by herbivores on decomposition processes (Bardgett and Wardle 2010). Several studies have shown that plants with foliage more palatable to generalist herbivores produce

50 faster-decomposing litter (Grime et al. 1996; Schädler et al. 2003; Pálková and Leps 2008; but see Kurokawa and Nakashizuka 2008). Therefore, it is hypothesized that selective feeding by herbivores results in slow decomposition of leaf litter, according to such a positive relationship between palatability and decomposability (Hartley and Jones 2004; Bardgett and Wardle 2010), i.e., highly palatable (= highly decomposable) plants are selectively consumed by herbivores in a plant community and, as a result, poorly palatable (= poorly decomposable) 
plants remain, and therefore, overall litter decomposition will be slow. The positive correlation between leaf palatability and litter decomposability results from the fact that plant defense traits against generalist herbivores, e.g., low nitrogen $(\mathrm{N})$ and phosphorus, and high tannins and lignin, also reduce decomposer activity (Bardgett and Wardle 2010). In most of the previous studies investigating the relationship between leaf palatability and litter decomposability, leaf palatability was determined by feeding experiments using slugs or crickets (Grime et al. 1996; Schädler et al. 2003; Pálková and Leps 2008; Kurokawa et al. 2010), which are suitable test organisms as generalist herbivores in determining leaf palatability. However, the leaf palatability derived from those herbivores

65 would not always be applicable to other insect herbivores, because leaf palatability would depend on the identity of insect species due to species-specific feeding adaptation to host plants (Keathley and Potter 2008). Hence, a positive correlation between leaf palatability and litter decomposability may not always be expected in all plant-insect systems (Kurokawa and Nakashizuka 2008). To understand the effects of insect herbivores on the decomposition process through selective feeding, it is important to evaluate the leaf palatability using insect herbivores which are likely to have a significant impact on the decomposition process. 
Moreover, insect herbivores can alter the energy and/or nutrient inputs to soil through return of the waste products, e.g., frass (Christenson et al. 2002; Frost \& Hunter 2007). Insect frass contains larger amounts of $\mathrm{N}$ and labile carbon (C) than does leaf litter (Lovett and Ruesink 1995; Madritch et al. 2007). It can stimulate microbial activity (Frost and Hunter 2004), and in turn increase the decomposition rate (Zimmer and Topp 2002), N mineralization, and N immobilization (Lovett and Ruesink 1995; Frost and Hunter 2007). In addition, insect frass quality is strongly influenced by host leaf quality, such as nitrogen and tannins (Madritch et al. 2007; Kagata and Ohgushi 2011) which are known to be chemicals determining the decomposition efficiency of leaf litter (Enríquez 1993; Kraus et al. 2003).

While selective feeding decreases the leaf litter produced by plants with high palatability, it would also lead to an increase in frass excreted by herbivores that fed on those plants. Therefore, the effects of selective feeding of insect herbivores on soil decomposition processes should be understood with respect to the inputs of both leaf litter and frass. However, the relationships between leaf palatability, litter decomposability and frass decomposability in herbivorous insects remain poorly known.

Here we examined the relationship between leaf palatability and decomposability of 
litter and frass, using the gypsy moth, Lymantria dispar (L.) (Lepidoptera: Lymantriidae), and 15 temperate deciduous tree species. Lymantria dispar is a suitable herbivorous insect for examining the relationship between palatability and decomposability in temperate deciduous forests for the following reasons: (1) L. dispar is an important pest for temperate deciduous trees and sometimes occurs at extremely high density (Kamata 2002), (2) L. dispar larvae are highly polyphagous but have a clear hierarchical feeding preference regarding tree species (Liebhold et al. 1995; Shields et al. 2003), and (3) defoliation by L. dispar larvae can have

95 significant impacts on decomposition and soil nutrient availability in a forest ecosystem (Lovett et al. 2002; Frost and Hunter 2004). Therefore, selective feeding and subsequent frass excretion by L. dispar larvae would have a potentially large impact on soil processes in temperate deciduous forests. We investigated the leaf palatability to $L$. dispar larvae by feeding tests, and conducted incubation experiments of leaf litter and larval frass in a laboratory microcosm to determine their decomposability.

\section{Materials and Methods}


Collection of plant leaves and litter

105

Plant materials used for the present study were collected in and around an experimental field of the Center for Ecological Research (Forest of CER; $35^{\circ} \mathrm{N}, 136^{\circ} \mathrm{E}$ ), Kyoto University in Shiga prefecture, central Japan. The secondary forest is dominated by Quercus serrata Murray (Fagaceae) and Pinus densiflora Siebold et Zucc. (Pinaceae), and includes more than

11050 tree species occurring naturally or artificially. We selected 15 tree species in 11 families for the experiment (Table 1), all of which were deciduous broad-leaved trees that are common in temperate forests. For each tree species, we collected fully expanded leaves from 4-6 tree individuals in late May to early June 2009 for a feeding experiment and frass collection. We also collected litter of each tree species underneath 4-6 tree individuals in late November

1152009 for a litter incubation experiment. The litter samples were air-dried for one month and stored at $-20{ }^{\circ} \mathrm{C}$ until the incubation experiment and chemical analysis.

Collection of L. dispar larvae and frass

120 Lymantria dispar is univoltine and overwinters as eggs. Larvae hatch in April and the larval 
period lasts two months through molting five or six times in central Japan (Furuno 1964).

Larvae of L. dispar are commonly observed on several trees in the forest of CER. Third- and fourth-instar larvae were collected from several tree species in and around the forest of CER in late April to early May 2009. The collected larvae (more than 400 individuals) were placed

125 with leaves of Q. serrata in rearing containers (3000 ml each) with a maximum of 20 individuals per container. The containers were kept in an environmental chamber at $25^{\circ} \mathrm{C}$ with a 16L8D light cycle. Leaves of $Q$. serrata were replaced with new ones every day. When the larvae reached sixth-instar (the last instar for most larvae, but some pass through seventh-instar until pupation, Furuno 1964), they were used for the feeding experiment and

130 frass collection. It is known that approximately $70 \%$ of the leaf consumption and frass excretion of immature stages occurs during the sixth-instar period in L. dispar (Furuno 1964). Hence, leaf consumption and frass excretion during this stage are critical for assessing the effects of selective feeding of $L$. dispar larvae on the decomposition process.

Frass of $L$. dispar for the incubation experiment was collected from 10-20 larvae

135 each of tree species. Prior to the frass collection, the larvae were kept for $24 \mathrm{~h}$ without diet to allow them to excrete the frass in their guts. The larvae were placed together with leaves of 
each tree species in a rearing container (3000 ml each) with a maximum of six individuals per container. They were kept in an environmental chamber at $25{ }^{\circ} \mathrm{C}$ with a $16 \mathrm{~L} 8 \mathrm{D}$ light cycle. Leaves of each tree species were replaced daily with new ones. The larval frass was collected

140 every day until pupation, and was stored at $-20{ }^{\circ} \mathrm{C}$ until the incubation experiment, after it was oven-dried at $60{ }^{\circ} \mathrm{C}$ for one week.

\section{Feeding experiment}

145 The relative leaf palatability of 15 deciduous tree species for $L$. dispar was determined by a non-choice feeding trial, using the sixth-instar larvae obtained from laboratory rearing as described above. Prior to the feeding trial, the larvae were kept for $24 \mathrm{~h}$ without diet to allow them to excrete the frass in their guts. One larva was placed in a 250-ml plastic cup with a few leaves, about $2 \mathrm{~g}$ fresh weight equivalent, for each tree species in an environmental chamber

150 at $25{ }^{\circ} \mathrm{C}$ with a 16 L8D light cycle. The larvae and leaves were weighed before the feeding trial. After $24 \mathrm{~h}$ the leaves were removed and the larvae were kept for $24 \mathrm{~h}$ without diet to allow them to excrete the frass in the gut. Thereafter, the larval frass was collected. Leaves, 
larvae, and frass were oven-dried at $60{ }^{\circ} \mathrm{C}$ for one week to determine dry weight. Leaves and frass were stored at $-20{ }^{\circ} \mathrm{C}$ until $\mathrm{C}$ and $\mathrm{N}$ analyses. Nine to 11 replicates were conducted for each tree species (Table 1).

Consumed leaf mass, as an index of leaf palatability, was determined as the difference in leaf dry mass between the start and the end of the feeding trial. Leaf dry mass of each tree species at the start of the feeding trial was estimated from the leaf water concentration, which was measured using additional samples ( $n=4-6$ for each tree species). The water concentration was determined from the difference between the fresh and dry mass, which was measured after oven-drying at $60{ }^{\circ} \mathrm{C}$ for one week. In addition, larval growth mass was also determined as the difference in larval dry mass between the start and the end of the feeding trial. Similarly, larval dry mass at the start of the feeding trial was estimated from their water concentration, which was measured using additional samples $(n=10)$. Palatability was also evaluated by excreted frass mass, because there was a strong positive correlation between consumed leaf mass and excreted frass mass (see Results). We noted that the palatability of $L$. dispar larvae observed in the present study may, to some degree, be affected by previous food experience prior to the feeding trials (Mattson and Scriber 1987), i.e., all 
larvae were reared on leaves of $Q$. serrata until the feeding trials.

170

Incubation experiment

Decomposability of leaf litter and insect frass was examined by incubation experiments in a

laboratory microcosm. Prior to the experiment, leaf litter and insect frass were roughly ground,

175 and mixed well for each treatment to obtain homogeneous quality. Litter or frass (750 mg)

was placed in a 50-ml glass vial with $750 \mathrm{ml}$ of soil and $2 \mathrm{ml}$ of distilled water, which brought

the samples to $60-70 \%$ of the water capacity of the substrates. Soil was added as a soil

microbe source, and soil-alone treatment was set as a control. The soil was collected

underneath ( $<5 \mathrm{~cm}$ in depth) several Q. serrata trees in the forest of CER in late November

180 2009. It was air-dried for one month and passed through a $2-\mathrm{mm}$ sieve, and was stored at $5{ }^{\circ} \mathrm{C}$

until use for the experiment. Fifteen replicates were established for each leaf litter and frass,

except for the frass originated from five tree species which were not examined due to

insufficient mass of frass for the experiment (Table 1). The test samples were incubated in the

dark at $25^{\circ} \mathrm{C}$ in an environmental chamber for four weeks. After incubation, the samples were 
oven-dried at $60{ }^{\circ} \mathrm{C}$ for two weeks to measure dry weight. The decomposability of litter and frass was determined by the reduction in dry mass during the incubation.

Carbon and nitrogen analyses

190 Prior to the analysis, all samples (fresh leaves, leaf litter, and insect frass) were ground to fine powder. Total C and N contents were determined using an elemental analyzer (JM 1000CN, J-Science Co., Ltd, Kyoto, Japan). Carbon and N contents of the frass originated from three tree species were not measured due to insufficient mass of the frass for the analyses (Table 1). Statistical analyses

Leaf consumption, frass excretion, and litter and frass decomposition were compared among plant species by one-way ANOVAs. Differences in C:N ratio among leaf, litter, and frass were tested by paired t tests. The difference between decomposition of litter and frass was also tested by paired $\mathrm{t}$ test. Relationships among litter and frass $\mathrm{C}: \mathrm{N}$ ratio, palatability and 
decomposability of litter and frass were evaluated using correlation coefficients (i.e., species-level analysis in which plant phylogeny was not considered). These relationships were also analyzed using phylogenetically independent contrasts (PICs) (Garland et al. 1992). A phylogenetic hypothesis for the studied plants was constructed using a recently inferred phylogenetic tree based on the Angiosperm Phylogeny Group classification (APG III 2009). This phylogenetic tree was resolved at the family level. Hence, we placed the genera as branches within families and species as branches within genera, where we had multiple species within a family (Fig. 1). We calculated PICs for each measured parameter, assuming that all branch lengths were equal. Because the statistical results in PICs were similar to the

210 results in species-level analysis (see Table 2), the results were described on the basis of PICs in the Results section. All analyses were conducted using JMP version 6 (SAS Institute Japan, Tokyo, Japan), except for the PICs which were analyzed using the package ape in R (R Development Core Team 2010).

\section{Results}


Feeding experiment

Larvae of $L$. dispar showed strong preferences for certain tree species: consumed leaf mass

220 differed significantly among tree species (ANOVA: $d f=14,139, F=17.39, P<0.0001$, Fig.

2a). Excreted frass mass also differed significantly among tree species (ANOVA: $d f=14,139$,

$F=22.48, P<0.0001$, Fig. $2 b)$. A strong positive correlation was detected between consumed

leaf mass and excreted frass mass $(r=0.88, P<0.0001$, Table 2$)$. Larvae converted

approximately $60 \%$ of consumed leaf mass to frass. Larval growth was significantly and

225 positively correlated with consumed leaf mass $(r=0.89, P<0.0001)$.

There was no significant correlation between leaf C:N ratio and consumed leaf mass

or between leaf $\mathrm{C}: \mathrm{N}$ ratio and excreted frass mass (Table 2). Frass $\mathrm{C}: \mathrm{N}$ ratio did not differ

from leaf C:N ratio (Paired t test, $d f=11, t=2.00, P=0.07$, Fig. 3a), and it was strongly,

positively correlated with leaf $\mathrm{C}: \mathrm{N}$ ratio $(r=0.91, P=0.0002$, Table 2$)$.

Incubation experiment 
Litter decomposability, expressed by dry weight loss during litter incubation, significantly differed among tree species (ANOVA: $d f=12,210, F=254.92, P<0.0001$, Fig. 2c). While

235 soil-alone treatment lost only $10.1 \mathrm{mg}$ of substrate mass, litter treatments lost 40.7-179.1 mg of mass during the four-week incubation. Frass decomposability also differed significantly among tree species (ANOVA: $d f=9,139, F=876.9, P<0.0001$, Fig. $2 d$ ), with loss of substrate mass ranging from 111.6 to $311.6 \mathrm{mg}$ during the incubation. A significant correlation between litter and frass decomposability was not detected ( $r=0.55, P=0.09$; Table 2). Frass C:N ratio was significantly lower than litter C:N ratio (Paired t test: $d f=11, t$ $=-4.55, P=0.0008$, Fig. 3a). Frass decomposability was significantly greater than litter decomposability (Paired t test: $d f=9, t=4.84, P<0.0009$, Fig. 3b). The reduction of mass in the frass incubation was approximately double compared to that in the litter incubation. Litter and frass decomposability were not correlated with litter or frass C:N ratio, respectively

245 (Table 2).

Relationships between palatability and decomposability 
Palatability, expressed by consumed leaf mass, was not correlated significantly with litter or

250 frass decomposability, although correlation coefficients showed negative values for each

relationship (Table 2, Fig. 4a and c). When excreted frass mass was also regarded as an index of palatability because there was a strong positive correlation between consumed leaf mass and excreted frass mass (Table 2), the excreted frass mass was significantly, negatively correlated with frass decomposability (Table 2 and Fig. 4d). On the other hand, it was not

255 correlated significantly with litter decomposability, although correlation coefficient was negative (Table 2 and Fig. 4c).

\section{Discussion}

Palatability to L. dispar

Lymantria dispar larvae are generalist herbivores, which can feed on over 500 plant species, and exhibit a clear hierarchical feeding preference (Liebhold et al. 1995; Shields et al. 2003). Several studies have examined factors involved in determining the host plant selection of $L$. 
dispar larvae, and demonstrated that the larvae preferred plant species that have no or low

levels of alkaloids in leaves (Barbosa and Krischik 1987; Shields et al. 2003), but the larval

preference was not affected by foliar tannins (Barbosa and Krischik 1987; Shields et al. 2003),

lignin (Brodeur-Campbell et al. 2006), or other C-based secondary metabolites (Barbosa and

Krischik 1987).

Tannins are common as anti-herbivore defensive substrates in a diverse group of

woody plants (Feeny 1970; Barbosa and Krischik 1987). However, there is increasing

evidence that tannins are not always a feeding deterrent against insect herbivores (Ayres et al.

1997; Forkner et al. 2004; Keathley and Potter 2008). In particular, they have little or no

effect on host selection of generalist insect herbivores, such as L. dispar and Popillia japonica

275 (Barbosa and Krischik 1987; Keathley and Potter 2008). In contrast, alkaloids have strong

feeding deterrence for the host plant selection of L. dispar larvae (e.g. Barbosa and Krischik

1987). It is known that alkaloids are rare or absent in Betulaceae, Fagaceae, and Salicaceae,

and are present in Magnoliaceae, Araliaceae, and Prunus (Rosaceae) (Barbosa and Krischik

1987). In fact, our results showed that the former plants were relatively preferred, while the

280 latter plants were rejected by L. dispar larvae. Although it is not clear whether other plant 
species used in the present study contain alkaloids, the leaf palatability to L. dispar larvae shown in the present study is most likely determined by foliar alkaloids, rather than by C-based secondary metabolites, such as tannins and lignin.

It is well known that the decomposability of litter is largely dependent on the quality of the litter, i.e., the concentrations of $\mathrm{N}$, phosphorus, tannins, and lignin, and their relative ratios across various plant species (Gallardo and Merino 1993; Aerts 1997; Kraus et al. 2003, Osono and Takeda 2005; Kurokawa and Nakashizuka 2008). In particular, tannins and lignin are important chemicals which suppress the litter decomposition rate (Kraus et al. 2003). Several studies demonstrated that litter with higher levels of tannins and/or lignin was decomposed more slowly for temperate deciduous trees (Gallard and Merino 1993; Osono and Takeda 2005). In contrast, the effects of N-based secondary metabolites, such as alkaloids, on litter decomposition have not been well explored. Siegrist et al. (2010) showed that alkaloids were not detected in the litter of a grass, Schedonorus arundinaceus, in spite of high levels of 
alkaloids in leaves, and that alkaloids had little effect on the decomposition process in a litter bag experiment with alkaloid addition. Therefore, it is most likely that tannins and/or lignin, but not alkaloids, were the important determinants of the decomposability shown in the present study.

Our results also showed that frass decomposability differed among tree species, and there was no strong correlation between litter and frass decomposability. Although litter and frass traits, such as C:N ratio and tannins, tend to be positively correlated with fresh leaf traits (Madritch et al. 2007; Kurokawa and Nakashizuka 2008), we did not find a significant

305 relationship between litter and frass C:N ratio. Hence, the chemical characteristics of the litter and frass may be determined in independent manners, resulting in the lack of a strong relationship between litter and frass decomposability. On the other hand, our results showed that frass was more rapidly decomposed than leaf litter. In general, insect frass contains larger amounts of N and labile C than does leaf litter (Lovett and Ruesink 1995; Madritch et al. 2007), which causes acceleration of the decomposition rate of frass (Zimmer and Topp 2002).

Although the frass $\mathrm{C}: \mathrm{N}$ ratio was lower than the litter $\mathrm{C}: \mathrm{N}$ ratio, frass and litter decomposability was not explained by the C:N ratio (see Table 2). Specific compounds, such 
as condensed tannins, rather than $\mathrm{C}: \mathrm{N}$ ratio, may be important in determining frass and litter decomposability (Hättenschwiler and Jørgensen 2010).

Relationships between palatability and decomposability

Several studies have shown that the palatability of leaves to generalist herbivores is positively correlated with litter decomposability (Grime et al. 1996; Schädler et al. 2003; Pálková and Leps 2008), which suggests that the factors determining leaf palatability might also determine litter decomposability (Bardgett and Wardle 2010). However, we found no positive correlations between palatability and decomposability in the system of gypsy moth and temperate deciduous trees. Similarly, Kurokawa and Nakashizuka (2008) found that while litter decomposability was largely determined by condensed tannins and lignin: $\mathrm{N}$ ratio, leaf palatability was not determined by such simple factors, resulting in the lack of a relationship between leaf palatability and litter decomposability in a tropical rain forest. The lack of a positive relationship between palatability and decomposability in the present study was probably also due to some difference between the key factors determining palatability and 
decomposability: leaf palatability to L. dispar larvae is likely to be determined by alkaloids, whereas litter and frass decomposability are likely to be determined by tannins and lignin.

Moreover, our results showed a negative correlation between excreted frass mass and frass decomposability. The correlation coefficient was also negative between leaf palatability and litter decomposability, although it was not statistically significant at $P=0.05$. These negative relationships indicate that the factors determining palatability and

335 decomposability may be negatively associated in our experimental system. As mentioned above, the palatability in this study was probably determined by alkaloids, while decomposability was probably determined by C-based secondary metabolites such as tannins and lignin. Several researchers have hypothesized that there is a negative association between C-based and N-based anti-herbivore defenses in plants (Bryant et al. 1983; Coley et al. 1985).

340 Actually, Stevens et al. (1995) showed that alkaloids were negatively correlated with tannin content in Crassulaceae plants. On the other hand, there is increasing evidence that no clear trade-offs are found between alkaloid defense and other C-based defenses (Steward and Keeler 1988; Koricheva 2002). Further understanding of the associations among multiple anti-herbivore defenses in plants would contribute to clarifying the mechanisms responsible 
345 for the palatability-decomposability relationships.

Ecosystem consequences of herbivore selective feeding

A positive association between leaf palatability and litter decomposability implies slower

350 litter decomposition due to selective feeding of generalist herbivores, because plants that

produce more decomposable litter are preferentially consumed (Hartley and Jones 2004;

Bardgett and Wardle 2010). However, the present study found no evidence of such a positive

relationship, and even showed a negative relationship between palatability and

decomposability. We also found that frass of $L$. dispar was decomposed faster than leaf litter.

355 These findings indicate that $L$. dispar larvae may accelerate the decomposition process in temperate deciduous forests through selective feeding on plants with relatively low litter decomposability and producing frass with higher decomposability than the litter. In addition, selective feeding by insect herbivores could also accelerate litter decomposition via induction of plant regrowth, i.e., selective feeding on plants that tolerate defoliation by mounting a regrowth response, which would produce litter with high decomposability (Hunter 2001). The 
effects of such herbivore-induced plant responses on litter decomposability were not examined in the present study. However, the plant responses to insect herbivory would be important factor determining the relationship between palatability and decomposability through changes in the litter decomposition process (Findlay et al. 1996; Uselman et al. 2011). Although the relationship between palatability and decomposability is critical for understanding the effects of selective feeding by herbivores on the decomposition process, this relationship is still a controversial issue because it may depend on the plant-herbivore systems, mechanistic pathways by which herbivores influence decomposition processes, and temporal/spatial scale (Hunter 2001). Our results were derived from short-terms and small-scale laboratory experiment, which may have influenced the observed palatability and/or decomposability. Nevertheless, present study would raise an important issue that there was no positive or negative relationship between palatability and decomposability for $L$. dispar, in contrast to previous studies that showed a positive relationship for slugs and crickets (Grime et al. 1996; Schädler et al. 2003; Pálková and Leps 2008). Further studies examining which types of herbivores show positive, negative or neutral relationships between palatability and decomposability will be needed to clarify how herbivores influence 
decomposition processes.

\section{Acknowledgements}

380 We thank I. Kojima and A. Matsumoto for identification of tree species, A. Kawakita for help

in statistical analyses, and E. Nakajima for English proofreading of the manuscript. This study was supported by a Grant-in-Aid for Scientific Research (B-20370010), and Kyoto University Global COE Program (A06). 


\section{References}

Aerts, R. (1997) Climate, leaf litter chemistry and leaf litter decomposition in terrestrial ecosystems: a triangular relationship. Oikos, 79, 439-449.

APG-III (2009) An update of the Angiosperm Phylogeny Group classification for the orders and families of flowering plants: APG III. Botanical Journal of the Linnean Society, 161, $105-121$

Ayres, M.P., Clausen, T.P., MacLean Jr., S.F., Redman, A.M., \& Reichard, P.B. (1997)

Diversity of structure and antiherbivore activity in condensed tannins. Ecology, 78, $1696-1712$.

395 Barbosa, P. \& Krischik, V.A. (1987) Influence of alkaloids on feeding preference of eastern deciduous forest trees by the gypsy moth Lymantria Dispar. The American Naturalist, 130, 53-69.

Bardgett, R.D. \& Wardle, D.A. (2010) Aboveground-Belowground Linkages Oxford University Press, New York.

400 Brodeur-Campbell, S.E., Vucetich, J.A., Richter, D.L., Waite, T.A., Rosemier, J.N., \& Tsai, C. 
(2006) Insect herbivory on low-lignin transgenic aspen. Plant-Insect Interactions, 35, 1696-1701.

Bryant, J.P., Chapin, F.S., \& Klein, B. (1983) Carbon/nutrient balance of boreal plants in relation to vertebrate herbivory. Oikos, 40, 357-368.

405 Chapman, S.K., Hart, S.C., Cobb, N.S., Whitham, T.G., \& Koch, G.W. (2003) Insect herbivory increases litter quality and decomposition: an extension of the acceleration hypothesis.

Ecology, 84, 2867-2876.

Christenson, L.M., Lovett, G.M., Mitchell, M.J., \& Groffman, P.M. (2002) The fate of nitrogen in gypsy moth frass deposited to an oak forest floor. Oecologia, 131, 444-452.

410 Coley, P.D., Bryant, J.P., \& Chapin, F.S. (1985) Resource availability and plant antiherbivore defense. Science, 230, 895-899.

Enríquez, S., Duarte, C.M., \& Sand-Jensen, K. (1993) Patterns in decomposition rates among photosynthetic organisms: the importance of detritus C:N:P content. Oecologia, $\mathbf{9 4 ,}$ 457-471.

415 Feeny, P. (1970) Seasonal changes in oak leaf tannins and nutrients as a cause of spring feeding by winter moth caterpillars. Ecology, 51, 555-581. 
Findlay, S., Carreio, M., Krischik, V., \& Jones, C.G. (1996) Effects of damage to living plants on leaf litter quality. Ecological Applications, 6, 269-275.

Forkner, P.E., Marquis, R.J., \& Lill, J.T. (2004) Feeny revisited: condensed tannins as anti-herbivore defenses in leaf-chewing herbivore communities of Quercus. Ecological Entomology, 29, 174-187.

Frost, C.J. \& Hunter, M.D. (2004) Insect canopy herbivory and frass deposition affect soil nutrient dynamics and export in oak mesocosms. Ecology, 85, 3335-3347.

Frost, C.J. \& Hunter, M.D. (2007) Recycling of nitrogen in herbivore feces: plant recovery, herbivore assimilation, soil retention, and leaching losses. Oecologia, 151, 42-53.

Furuno, T. (1964) On the feeding quantity of the gypsy moth (Lymantria dispar Linne) and the camphor silk moth (Dictyoploca japonica Bulter). Journal of the Japanese Forest Society, 46, 14-19.

Gallardo, A. \& Merino, J. (1993) Leaf decomposition in two mediterranean ecosystems of southwest Spain: influence of substrate quality. Ecology, 74, 152-161.

Garland, T., Harvey, P.H., \& Ives, A.R. (1992) Procedures for the analysis of comparative data using phylogenetically independent contrasts. Systematics Biology, 41, 18-32. 
Grime, J.P., Cornelissen, J.H., \& Hodgson, J.G. (1996) Evidence of a causal connection between anti-herbivore defense and the decomposition rate of leaves. Oikos, 77, 489-494.

435 Hartley, S.E. \& Jones, T.H. (2004). Insect herbivores, nutrient cycling and plant productivity. Insects and Ecosystem Function (ed. by W.W. Weisser and E. Siemann), pp. 27-52. Springer-Verlag, Berlin.

Hättenschwiler, S. \& Jørgensen, H.B. (2010) Carbon quality rather than stoichiometry controls litter decomposition in a tropical rain forest. Journal of Ecology, 98, 754-763.

440 Hunter, M. D. (2001) Insect population dynamics meets ecosystem ecology: effects of herbivory on soil nutrient dynamics. Agricultural and Forest Entomology, 3, 77-84

Kagata, H. \& Ohgushi, T. (2011) Ingestion and excretion of nitrogen by larvae of a cabbage armyworm: the effects of fertilizer application. Agricultural and Forest Entomology, 13, 143-148.

445 Kamata, N. (2002) Outbreaks of forest defoliating insects in Japan, 1950-2000. Bulletin of Entomological Research, 92, 109-117.

Keathley, C.P. \& Potter, D.A. (2008) Quantitative resistance traits and suitability of woody plant species for a polyphagous scarab, Popillia japonica Newman. Environmental 
Entomology, 37, 1548-1557.

450 Koricheva, J. (2002) The carbon-nutrient balance hypothesis is dead; long live the

carbon-nutrient balance hypothesis ? Oikos, 98, 537-539.

Kraus, T.E.C., Dahlgren, R.A., \& Zasoski, R.J. (2003) Tannins in nutrient dynamics of forest ecosystems - a review. Plant and Soil, 256, 41-66.

Kurokawa, H. \& Nakashizuka, T. (2008) Leaf herbivory and decomposability in a Malaysian tropical rain forest. Ecology, 89, 2645-2656.

Kurokawa, H., Peltzer, D.A., \& Wardle, D.A. (2010) Plant traits, leaf palatability and litter decomposability for co-occurring woody species differing in invasion status and nitrogen fixation ability. Functional Ecology, 24, 513-523.

Liebhold, A.M., Gottschalk, K.W., Muzika, R., Montgomery, M.E., Young, R., O'Day, K., \& Kelley, B. (1995) Suitability of North American tree species to the gypsy moth: a summary of field and laboratory tests USDA Forest Service, Delaware, Ohio.

Lovett, G.M. \& Ruesink, A.E. (1995) Carbon and nitrogen mineralization from decomposing gypsy moth frass. Oecologia, 104, 133-138.

Lovett, G.M., Christenson, L.M., Groffman, P.M., Jones, C.G., Hart, J.E., \& Mitchell, M.J. 
Madritch, M.D., Donaldson, J.R., \& Lindroth, R.L. (2007) Canopy herbivory can mediate the influence of plant genotype on soil processes through frass deposition. Soil Biology \& Biochemistry, 39, 1192-1201.

Mattson, W.J. \& Scriber, J.M. (1987). Nutritional ecology of insect folivores of woody plants: nitrogen, water, fiber, and mineral considerations. Nutritional Ecology of Insects, Mites, Spiders, and Related Invertebrates (ed. by F. Slansky \& J.G. Rodrigues), pp. 105-146. John Wiley \& Sons, New York.

Osono, T. \& Takeda, H. (2005) Decomposition of organic chemical components in relation to nitrogen dynamics in leaf litter of 14 tree species in a cool temperate forest. Ecological $475 \quad$ Research, 20, 41-49.

Pálková, K. \& Leps, J. (2008) Positive relationship between plant palatability and litter decomposition in meadow plants. Community Ecology, 9, 17-27.

Schädler, M., Jung, G., Auge, H., \& Brandl, R. (2003) Palatability, decomposition and insect herbivory: patterns in a successional old-field plant community. Oikos, 103, 121-132.

480 Schmitz, O.J. (2009) Effects of predator functional diversity on grassland ecosystem function. 
Ecology, 90, 2239-2345.

Shields, V.D.C., Broomell, B.P., \& Salako, J.O.B. (2003) Host selection and acceptability of selected tree species by gypsy moth larvae, Lymantria dispar (L.). Annals of the Entomological Society of America, 96, 920-926. responsible for endophyte-associated reductions in tall fescue decomposition rates.

Functional Ecology, 24, 460-468.

Stevens, J.F., Hart, H.T., van Ham, R.C.H.J., Elema, E.T., van den Ent, M.M.V.X., Wildeboer, M., \& Zwaving, J.H. (1995) Distribution of alkaloids and tannins in the Crassulaceae. Biochemical Systematics and Ecology, 23, 157-165.

Steward, J.L. \& Keeler, K.H. (1988) Are there trade-offs among antiherbivore defenses in Ipomoea (Convolvulaceae)? Oikos, 53, 79-86.

Uselman, S.M., Snyder, K.A., \& Blank, R.R. (2011) Insect biological control accelerates leaf litter decomposition and alters short-term nutrient dynamics in a Tamarix-invaded riparian ecosystem. Oikos, 120, 409-417.

Wardle, D.A. \& Bardgett, R.D. (2004). Indirect effects of Invertebrate herbivory on the 
decomposition subsystem. Insects and Ecosystem Function (ed. by W.W. Weisser and E.

Siemann), pp. 53-70. Springer-Verlag, Berlin.

Yang, L.H. (2006) Interactions between a detrial resource pulse and a detritivore community.

$500 \quad$ Oecologia, 147.

Zimmer, M. \& Topp, W. (2002) The role of coprophagy in nutrient release from feces of phytophagous insects. Soil Biology \& Biochemistry, 34, 1093-1099. 
Table 1: Tree species used in the present study. Sample size for leaf and litter collection, and number of replications in the feeding trial, litter and frass incubation experiments are also presented. Blanks indicate no data. Tree = number of tree individuals for which leaves and litter were collected. Feeding $=$ number of replications in the feeding trial. $\mathrm{L}$ inc $=$ number of replications of the litter incubation. $\mathrm{F}$ inc $=$ number of replications of frass incubation. $\mathrm{L} \mathrm{CN}=$ sample size in $\mathrm{C}$ and $\mathrm{N}$ analyses for leaves and litter. $\mathrm{F} \mathrm{CN}=$ sample size in $\mathrm{C}$ and $\mathrm{N}$ analyses for frass.

\begin{tabular}{|c|c|c|c|c|c|c|c|}
\hline \multirow[t]{2}{*}{ Family } & \multirow[t]{2}{*}{ Species } & \multicolumn{6}{|c|}{ Sample size or replication } \\
\hline & & Tree & Feeding & L inc & F inc & $\mathrm{LCN}$ & F CN \\
\hline Magnoliaceae & Magnolia obovata Thunb. & 5 & 11 & 15 & & 5 & 11 \\
\hline Betulaceae & Alnus sieboldiana Matsumura & 6 & 11 & 15 & 15 & 6 & 11 \\
\hline \multirow[t]{3}{*}{ Fagaceae } & Castanea crenata Siebold \& Zucc. & 5 & 10 & 15 & 15 & 5 & 10 \\
\hline & Quercus acutissima Carruth. & 6 & 9 & 15 & 15 & 6 & 9 \\
\hline & Quercus serrata Murray & 6 & 10 & 15 & 15 & 6 & 10 \\
\hline Ulmaceae & Zelkova serrata Makino & 6 & 10 & 15 & 15 & 6 & 10 \\
\hline \multirow[t]{2}{*}{ Rosaceae } & Prunus grayana Maxim. & 6 & 10 & 15 & & 6 & 10 \\
\hline & Prunus jamasakura Nakai & 6 & 11 & 15 & & 6 & \\
\hline Fabaceae & Wisteria floribunda (Willd.) & 4 & 10 & 15 & 15 & 4 & 10 \\
\hline Euphorbiaceae & Mallotus japonicus (Thunb.) & 6 & 10 & 15 & 15 & 6 & 10 \\
\hline \multirow[t]{2}{*}{ Salicaceae } & Salix eriocarpa Franch. \& Sav. & 5 & 10 & 15 & 15 & 5 & 10 \\
\hline & Populus tremula L. & 6 & 9 & 15 & 15 & 6 & 9 \\
\hline Anacardiaceae & Rhus javanica L. & 6 & 11 & 15 & 15 & 6 & 11 \\
\hline \multirow[t]{2}{*}{ Clethraceae } & Clethra barbinervis Siebold \& & 6 & 11 & 15 & & 6 & \\
\hline & Zucc. & & & & & & \\
\hline \multirow[t]{2}{*}{ Araliaceae } & Gamblea innovans (Siebold \& & 6 & 11 & 15 & & 6 & \\
\hline & Zucc.) & & & & & & \\
\hline
\end{tabular}


Table 2: Correlation coefficients in species-level analyses (above the diagonal) and in phylogenetically independent contrasts (below the diagonal and shown by bold) between measured parameters, i.e., leaf C:N ratio, litter C:N ratio, frass C:N ratio, leaf consumption,

520 frass excretion, litter decomposition, and frass decomposition. They were explained on the basis of the analyses in phylogenetically independent contrasts in the text. ***: $\mathrm{P}<0.0001$, **: $\mathrm{P}<0.001, *: \mathrm{P}<0.05,{ }^{(*)}: \mathrm{P}<0.1$.

\begin{tabular}{|c|c|c|c|c|c|c|c|}
\hline & Leaf CN & Litter CN & Frass CN & Consumption & Excretion & Litter dec & Frass dec \\
\hline Leaf CN & & 0.23 & $0.90 * * *$ & -0.16 & -0.21 & -0.37 & 0.26 \\
\hline Litter CN & 0.17 & & -0.03 & -0.29 & -0.40 & -0.21 & 0.37 \\
\hline Frass CN & $0.91 * *$ & -0.08 & & 0.13 & -0.01 & -0.34 & 0.38 \\
\hline Consumption & -0.13 & -0.16 & 0.06 & & $0.93 * * *$ & $-0.48^{(*)}$ & $-0.59^{(*)}$ \\
\hline Excretion & -0.18 & -0.33 & 0.01 & $0.88 * * *$ & & $-0.52 *$ & $-0.74 *$ \\
\hline Litter dec & -0.39 & -0.30 & -0.36 & -0.40 & $-0.46^{(*)}$ & & 0.46 \\
\hline Frass dec & 0.01 & -0.48 & -0.03 & -0.35 & $-0.63 *$ & $0.55^{(*)}$ & \\
\hline
\end{tabular}


Figure legends

Fig. 1. Phylogenetic hypothesis used for calculation of phylogenetically independent contrasts, which is based on the Angiosperm Phylogeny Group classification (APG III $530 \quad$ 2009).

Fig. 2. (a) Consumed leaf mass, (b) frass mass excreted by L. dispar larvae in the feeding experiment (c) decrease of litter mass, and (d) decrease of frass mass in the incubation experiment. Means with SE are presented.

Fig. 3. (a) C:N ratio in fresh leaves, litter, and frass, and (b) decomposition of litter and frass. Decomposition is shown as decrease of substrate mass (mg). Means with SE are presented.

Fig. 4. Relationship between palatability and decomposability as indicated by relationships between: (a) leaf consumption and litter decomposition, (b) frass excretion and litter decomposition, (c) leaf consumption and frass decomposition, and (d) frass excretion and frass decomposition. Statistical values were based on the analyses using phylogenetically independent contrasts (see also Table 2). 
Fig. 1

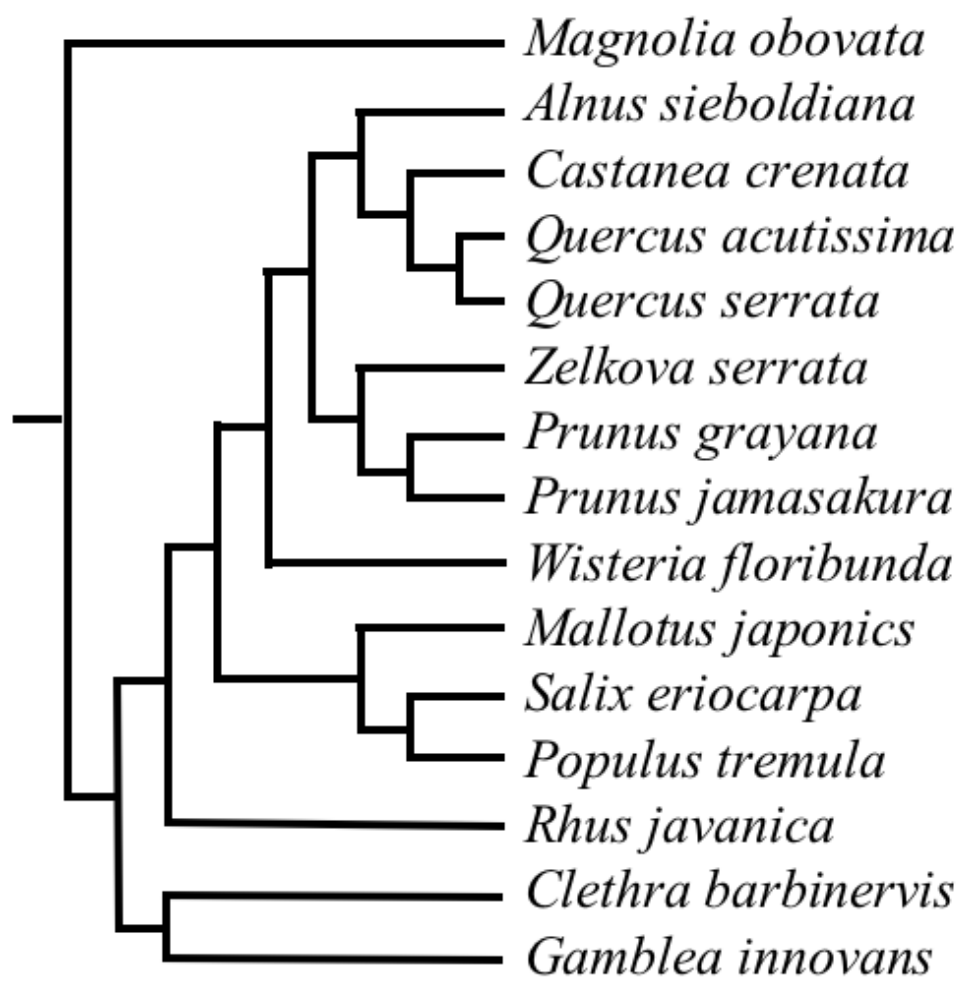


545 Fig.2

(a)

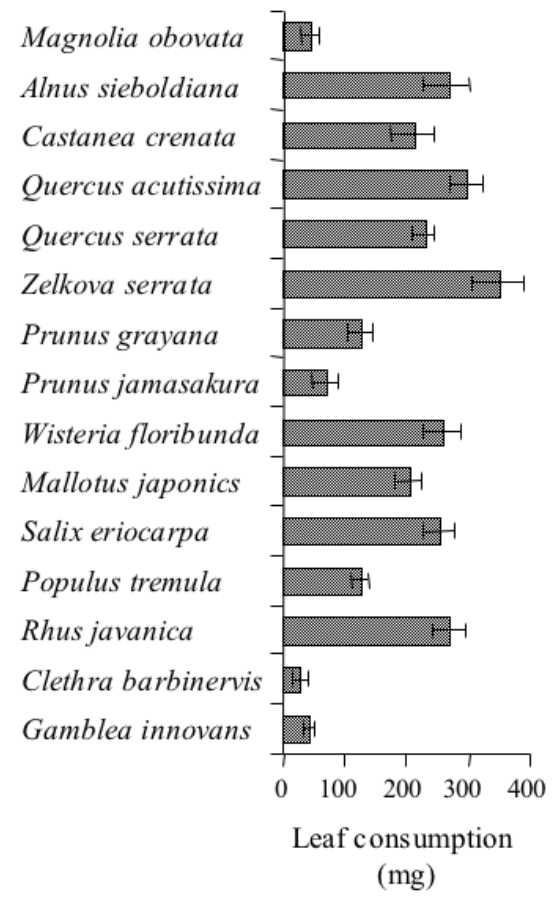

(b)

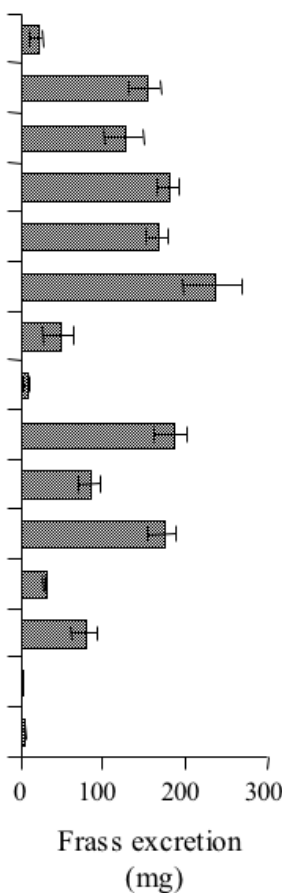

(c)

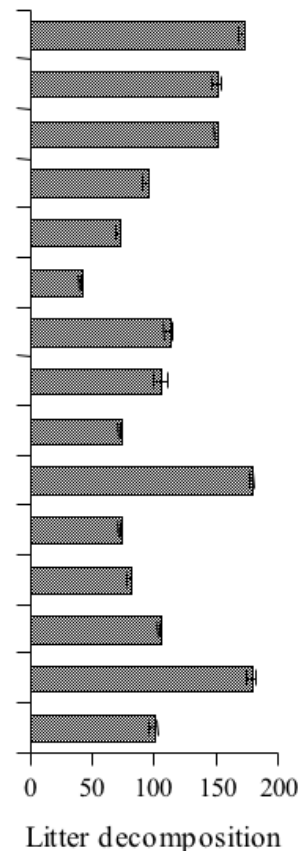

(mg) (d)

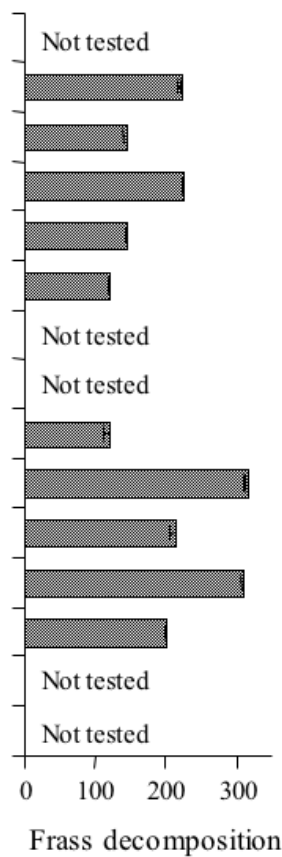

(mg) 
Fig.3
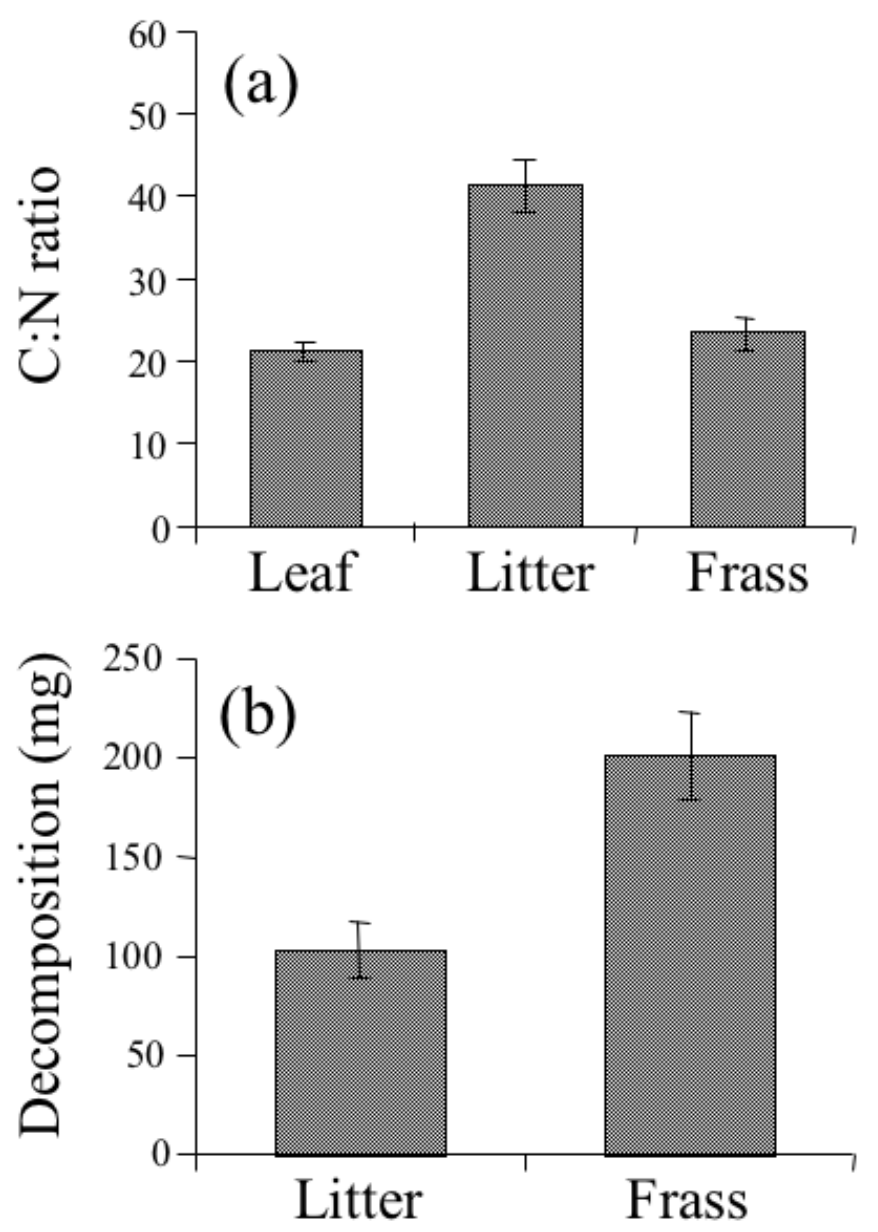
Fig.4
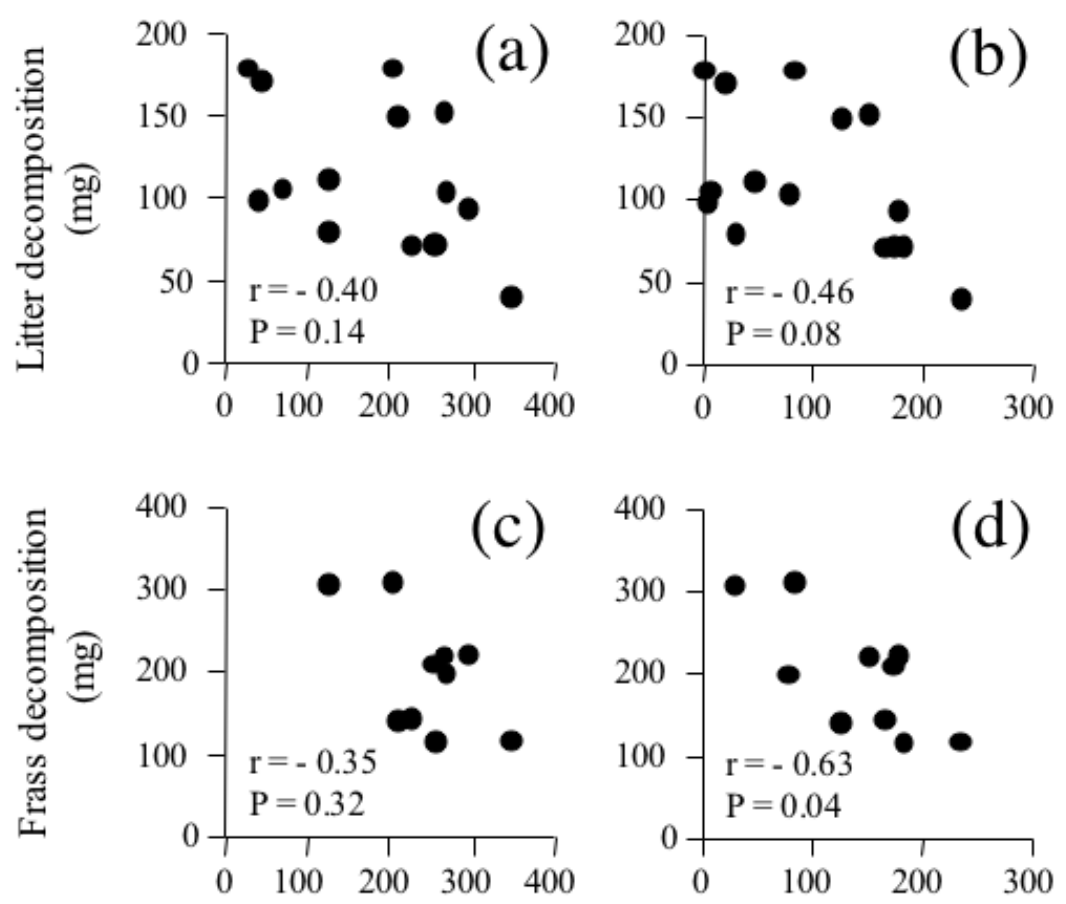

Leaf consumption (mg)

Frass excretion (mg) 